\title{
SCENARIO-BASED STRATEGY DEVELOPMENT FOR INTEGRATED WATER MANAGEMENT
}

\author{
P. KATSIARDI ${ }^{1}$ \\ E. MANOLI \\ C. KARAVITIS ${ }^{2}$ \\ D. ASSIMACOPOULOS ${ }^{1 *}$
}

Selected from papers presented in $9^{\text {th }}$ International Conference on Environmental Science and Technology (9CEST2005)

1-3 September 2005, Rhodes island, Greece
${ }^{1}$ Department II, School of Chemical Engineering National Technical University of Athens, Zografou Campus 9 Heroon Polytechniou st., 15780 Athens, Greece

${ }^{2}$ Agricultural University of Athens 75 lera Odos st., 11855 Athens, Greece

*to whom all correspondence should be addressed Tel: +(30) 2107723 218; fax: +(30) 2107721196 e-mail: assim@chemeng.ntua.gr

\section{ABSTRACT}

This paper presents a step-by-step methodological approach for the development and evaluation of strategies for water deficient regions. The primary focus of the approach followed was the mitigation of water stress, while applying the principles of Integrated Water Resources Management and the EU Water Framework Directive.

The participation of Stakeholders and end-users through consultations was a key point in the methodology followed. Stakeholders and actors were approached and their opinions on Water Management were collected and integrated into a list of measures and instruments suited and available for implementation, forming the basic assumptions governing the strategy formulation process for a region. Comprehensive scenarios were developed and examined for each of the selected options, through a prototype Decision Support System (WSM DSS), in order to obtain an initial ranking with regard to their suitability and performance. Then, the strategy formulation involved the integration of options on a regional basis in a set timeframe, based on their previous estimated performance and technical considerations with regard to their implementation.

To achieve the set-out goals and principles two distinct strategies were evaluated and compared, one reflecting the traditional and current practices and policies, and one closely following the principles of Integrated Water Resources Management (IWRM). The developed Strategies were evaluated against each other and against the reference state of the water system, using a set of appropriate indicators for performance, cost, environmental and social impacts. Alternative pricing schemes were also explored in order to achieve a desired level of cost recovery for water services, and determine its effect on Strategy implementation. The developed strategies were re-examined and adjusted on the basis of the cost recovery structures, to account for the effects of price elasticities, and an overall evaluation was obtained enabling a final comparison.

The methodology is illustrated through an exemplary application for the island of Paros, Greece. On the basis of the perceptions of different stakeholders, alternative water management strategies were developed and evaluated, and recommendations were made towards the mitigation of impacts caused by the high temporal water imbalance in the island.

KEYWORDS: Integrated Water Resources Management, Strategic Planning, Cost recovery. 


\section{INTRODUCTION}

Sustainability, in the words of the Brundtland Report [1], is defined as "Meeting the needs of the present generation without compromising the ability of future generations to meet their needs". This has been one of the major concepts behind Integrated Water Resources Management (IWRM) efforts in recent years, and a founding principle of the EU Water Framework Directive 2000/60/EC (WFD). The WFD seeks to promote the sustainable management of water resources in the member states, through a number of measures aiming to alleviate the pressures exerted on existing water bodies and to achieve their good environmental status, in an effort to ensure the long-term protection of all available water resources.

In the context of the WFD, water resource planning and management should be performed for a long time horizon, taking into account the long-run accumulative effects and addressing potential future changes and uncertainties. A water resources management strategy is different to the master plans that countries and/or regions develop. Master Plans tend to be project-oriented, and the product of a master plan is often a specific set of projects to be undertaken, with the corresponding investments. Master plans can follow an accepted strategy, as a set of interventions planned within its framework; however, without reference to a specific strategy, a master plan can easily disregard the long-term issue of building water management capacity [2]. On the other hand, the product of national strategy formulation is not a specific set of projects, although it is based on such. A strategy should address a wide variety of aspects of water resources management, including the institutional and human resources framework and the enhancement of water management capacity.

At the regional level, water related issues are managed in different units, with varying degrees of cohesion and coordination, which are mostly related with the level of administration in the overall planning and management [3]. Among others, the most pressing issue that has to be addressed by regional water strategies is the integration of sectoral approaches. These may concern the sub-regional analysis of the economic, social and environmental feasibility of irrigation rehabilitation, the energy/water nexus, water and salt strategies, and water and wastewater strategies in industrialized areas. Such cross-sectoral issues, although integrated in the overall national policy and action plans, should also be addressed locally at the River Basin District or catchment level, since they usually constitute a source of conflict between local stakeholders, actors and end-users.

This paper aims to present a step-by step methodology for developing integrated water management strategies on a regional/river basin level. The strategies, based on water management options identified through stakeholder consultation, were modelled, formulated and evaluated using a prototype Decision Support System (WSM DSS) [4]. The WSM DSS allocates water from available and user-defined sources to user-defined uses, taking into account user-defined priorities for each use and the selected strategy under different scenarios, and assesses the impact of this allocation.

Through the estimation of water supply requirements, interventions and costs, the system was used to identify and evaluate appropriate responses for mitigating water stress in the island of Paros, Greece. Additionally a cost recovery scheme was formulated taking into account on the economic tools and principles underlined in the Water Framework Directive.

\section{METHODOLOGY FOR STRATEGY FORMULATION}

The sustainable management of water resources requires the integration of a number of approaches and instruments, illustrated in Figure 1, within the framework of an IWRM Strategy. A strategy is primarily defined by a) its target and b) the set of instruments available/acceptable to the decision-maker. In order to produce a meaningful output, the process of strategic planning takes into account several variables, following a well- 
defined methodology.

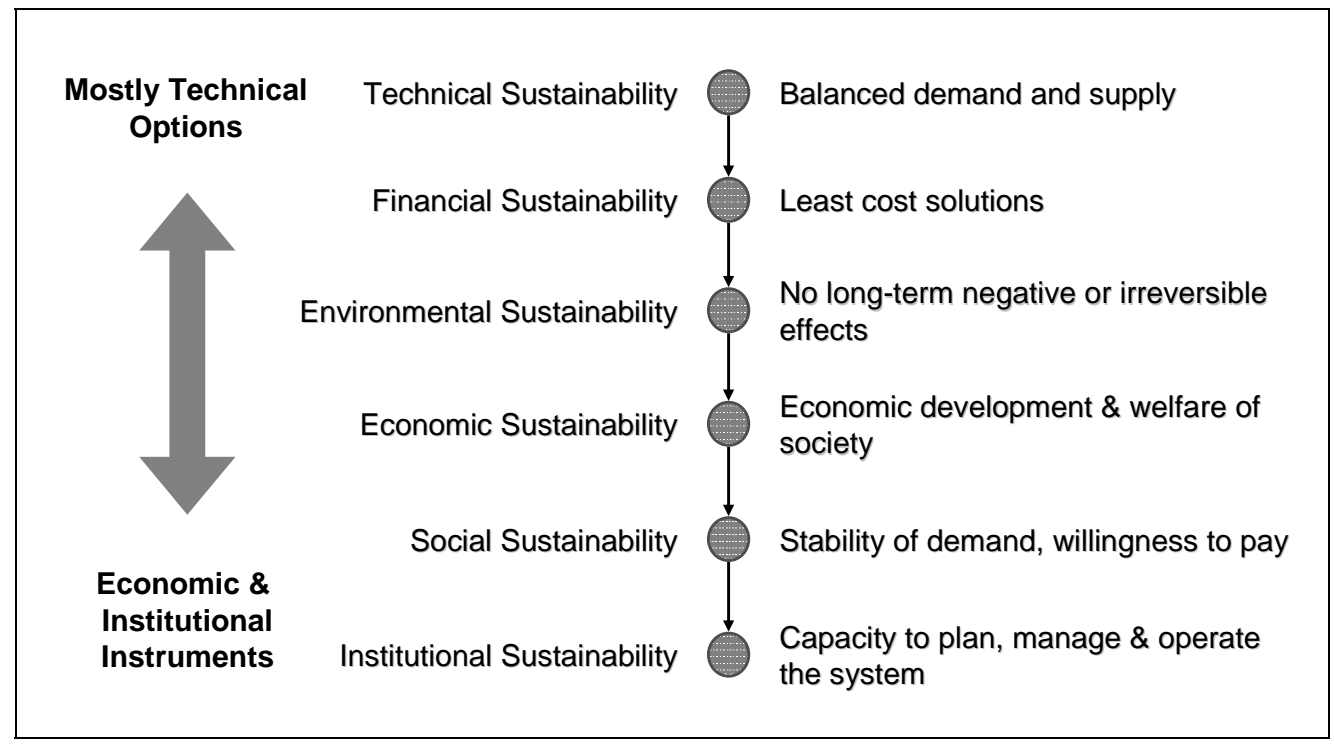

Figure 1. Components of the Sustainability Issue

The methodology adopted is elaborated into two stages (Figure 2). In the first stage, the Water Resources Management Strategies are developed, analysed and evaluated; these aim primarily at the coverage of demand and the resolution of the conflicts arising from water shortage and/or overexploitation, while minimizing the associated costs and environmental impacts. In the second stage, an additional element is introduced in the form of a Cost Recovery Strategy, which attempts to achieve a set level of recovery of the costs associated water provision, as well as the environmental and resource costs associated with the process. Throughout these two stages, the governing principles are those of Integrated Water Resources Management, defined as "a process that promotes the co-ordinated development and management of water, land and related resources, in order to maximize the resultant economic and social welfare in an equitable manner without compromising the sustainability of vital ecosystems" [3], namely [5]:

- The goal of Equity; in addition to an equitable allocation of the water resource in itself, this goal also involves the equitable distribution of costs equitably among the water users, including households, the tourist industry, the farmers and Industry.

- The goal of Environmental Sustainability, mainly through the mitigation of the impacts incurred in the production and supply of water, which in arid and semi arid areas dependent on groundwater involves the reduction of drillings to sustainable levels.

- The goal of Economic efficiency, involving the minimisation of costs and maximization of output associated with the provision of water, achieved through the selection and application of management options that are most efficient and making use of best practices, new technologies and improvements.

The process that has been followed to achieve these goals is illustrated in Figure 2 and includes 2 major stages with a total of 7 steps.

Steps 1 and 2 of the approach are strongly related to stakeholder consultation, since a number of developed strategies in the past, even if essential failed to win stakeholders' acceptance. Work undertaken in these steps involves the identification of potential stakeholders, the selection of representatives, the organisation of awareness meetings and the identification and synthesis of opinions, wishes and expectations. 


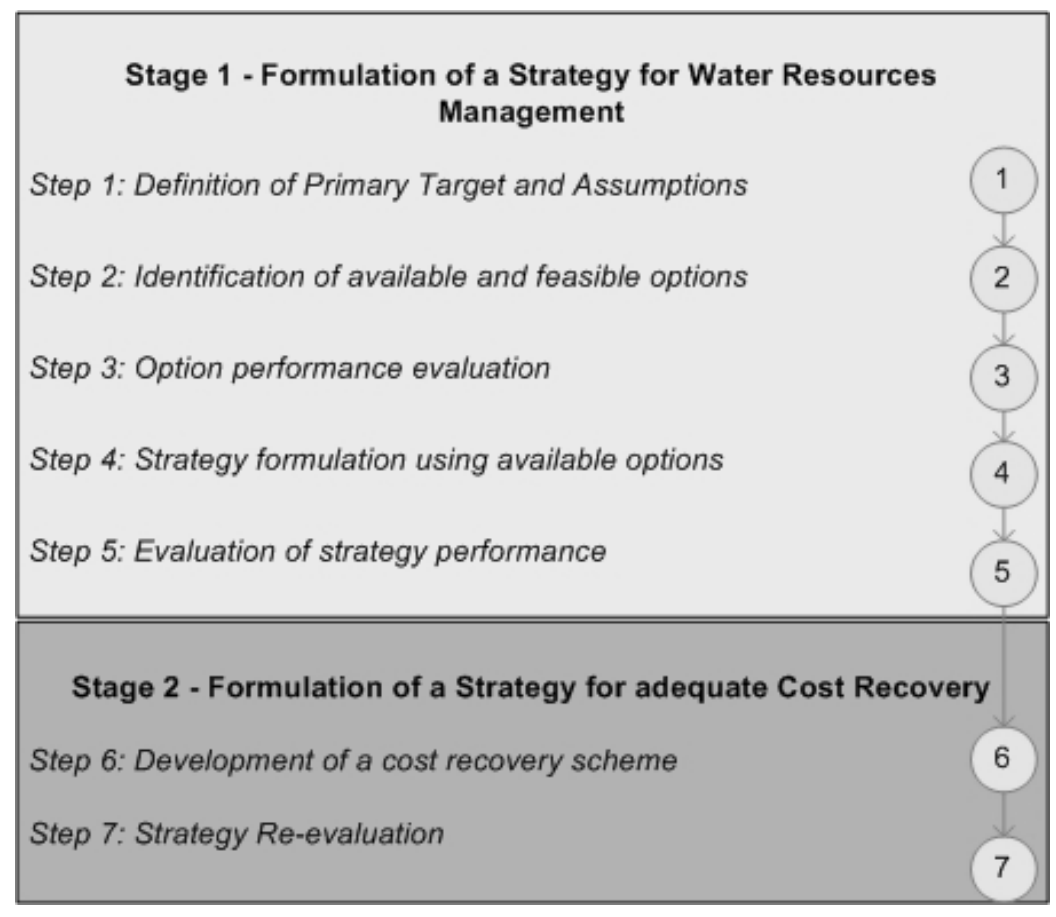

Figure 2. The process of Strategy Development

Step 3 involves the evaluation of the performance of the proposed interventions through their modelling and simulation using the WSM DSS, and the derivation of the Performance Matrix that permits their ranking. This evaluation is performed under different combinations of scenarios on pressures (demand and availability), in order to define the maximum extent of application, technical constraints, incurred costs, and associated environmental impacts. Step 4 involves the integration of the most suitable options in coherently formulated water management strategies. Their actual formulation involves the selection of the instruments, based on the recommendations of Step 2 and the results of Step 3. The definition of an appropriate timeframe is based on successive simulations in WSM DSS, taking into account technical and environmental constraints, and the achievement of the set out targets. In Step 5, strategies are evaluated against each other, as well as the reference case for the water system. From a wide set of available indicators, those that are chosen on a preliminary basis consist of: (a) the relative sustainability index for demand coverage, including criteria for reliability, resilience, and vulnerability [7], (b) financial costs incurred from the application of the strategy and the provision of water services, (c) associated environmental impacts and costs, including groundwater and surface water abstraction costs, pollution costs and (d) resource costs incurred by the allocation of water to specific uses. Subject to userdefined criteria, these indicators can be used to provide an overall score for each strategy.

The approach is complemented through the development of appropriate cost recovery schemes, taking into account institutional and governance framework constraints and the need for the adequate contribution of water uses to costs incurred by water services [6]. In Step 6, an appropriate cost recovery target is set, depending on affordability criteria. Then, the current pricing scheme is analysed with respect to the recovery of financial, environmental and resource costs, thus providing an estimate of the increases in price required in order to reach the set targets. As the elevated water prices will in most cases influence the water demand, each strategy is then re-formulated and re-evaluated in Step 7, using the same indicators as in Step 5. 


\section{APPLICATION OF THE METHODOLOGY IN THE ISLAND OF PAROS, GREECE}

The island of Paros, which faces intense supply coverage problems during the summer tourist season due to insufficient planning, lends itself to the analysis of adequate, suitable Strategies that will promote the solution of the temporary shortage problems without adversely affecting the prosperity of the island. Under this context, the goal of the formulation of scenarios and strategies for Paros Island (Step 1) is to reconcile the supply and demand of water, while at the same time attempting to ensure the sustainability of supply and the achievement of environmental goals through protection of the vulnerable groundwater resources. The targets set for the analysis were to meet (a) at least $80 \%$ of the domestic and irrigation needs in the peak summer period, and (b) $100 \%$ of the domestic and irrigation needs during the rest of the year. The formulated strategies aim at medium to long-tem planning, and take into account a 25 year horizon, (period 2005 2030). Design and planning assume average availability conditions, while the demand trend used is the Business-As-Usual demand scenario, assuming a 1.5\% yearly increase for population \& tourism growth.

In Step 2 potential policy options that could address these targets have been identified through consultation with local stakeholders, who, according their goals and economic interests, proposed a number of different approaches. For the Municipality of Paros, water management should concentrate mainly on supply enhancement through structural interventions, such as boreholes, interception dams and desalination. The local Water Utility (DEYAP) holds the opinion that new measures should concentrate on the more efficient use of water resources, through technological adjustments, conservation campaigns and regulation of groundwater abstractions. They recognize the necessity for structural interventions; however they would like to promote more technical solutions, such as desalination, without abandoning the traditional practices of groundwater exploitation. The Union of Agricultural Associations and the Union of Hotel Room Owners have similar points of view, considering that an expansion of desalination capacity would be an efficient solution for dealing with the water scarcity problems. They are increasingly aware of the limited available supply and recognize the benefits of technological adjustments and rationalization of water usage. As a result of the consultation process, a series of options were identified and selected for evaluation in order to formulate alternative responses. Those are outlined in Figure 3.

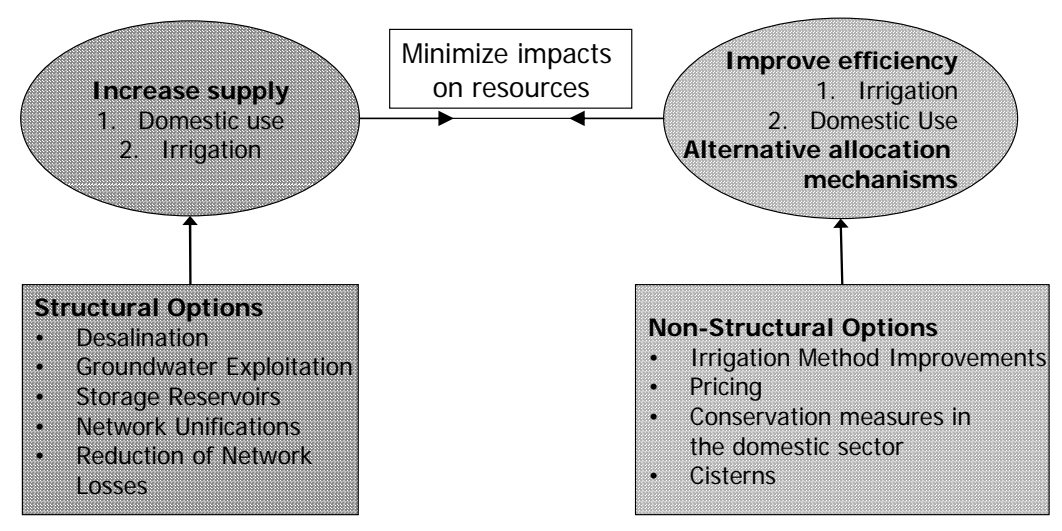

Figure 3. Summary of identified feasible and available options for the island of Paros

On a third level, the behaviour of the water system under each management option was assessed under three alternative baseline scenarios, a best case scenario, a worst case scenario and a business as usual scenario [8]. Those scenarios have been derived from the combinations of availability and demand projections, including scheduled interventions as these are planned, and constitute the reference scenarios under which the different management options were evaluated. Figure 3 presents an example of the results obtained from irrigation efficiency improvements. Environmental costs were 
associated with impact mitigation measures for groundwater (over)abstractions and pollution generated from domestic uses.

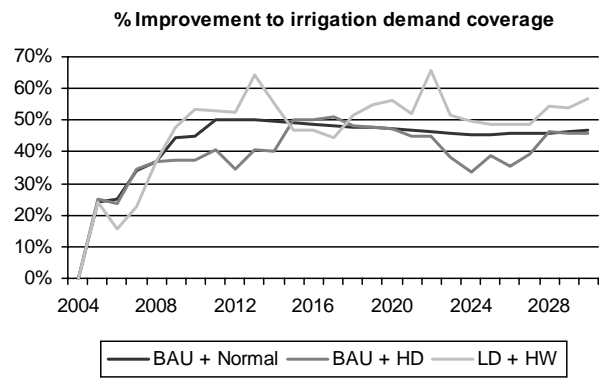

(a)

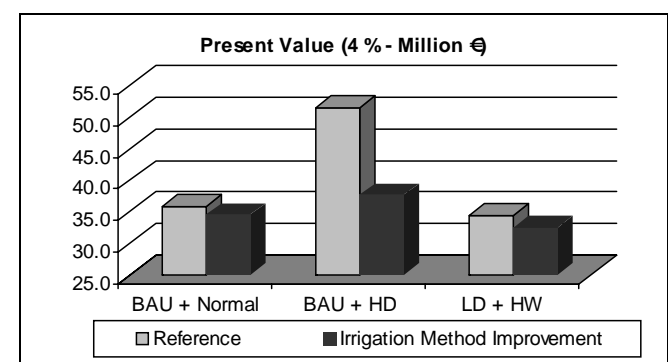

(b)

Figure 4. Example of results obtained from the simulation of irrigation method improvements (a) \% improvement of irrigation demand coverage with respect to reference scenarios (b) comparison of environmental costs

The selection of the most effective combination of measures from the identified and modelled options, was based on a Performance Matrix derived from the simulation results. These are presented in numerical and normalised form in Table 1.

In Step 4 combinations of water management options were formulated into two alternative Strategies, to be evaluated against each other and against the reference case. Strategy 1 focuses on the current "hard-path" responses, incorporating mostly supplyoriented measures, and the newest techniques and methods applied and proposed, such as desalination [9]. Strategy 2 implements a "soft-path" approach, including mostly demand management measures and small-scale, decentralised structural interventions where required. Measures incorporated in each Strategy are presented in Table 2. The temporal planning of option application was based on the technical aspects of the selected options (e.g. lifetime, construction time etc), as well as the performance of each option. The results of the evaluation of the two strategies are presented in brackets in Table 3, while their effectiveness in achieving the targets of the analysis is portrayed in Figure 5.

Table 1. Option performance matrix

\begin{tabular}{|c|c|c|c|}
\hline Option & $\begin{array}{l}\text { Relative Sustainability } \\
\text { Index for Demand } \\
\text { Coverage }\end{array}$ & $\begin{array}{l}\text { Financial } \\
\text { Cost }\end{array}$ & $\begin{array}{c}\text { Environmental } \\
\text { Cost }\end{array}$ \\
\hline Reference & $0.008(-)$ & $27.43(\star \star \star \star)$ & $40.66(-)$ \\
\hline Network Unifications & $0.154(* *)$ & $27.57(\star \star \star \star)$ & $39.16(* *)$ \\
\hline GW Exploitation & $0.213(* \star \star)$ & $27.80(\star \star \star \star)$ & $39.90\left(^{*}\right)$ \\
\hline Desalination & 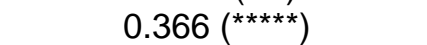 & $35.57\left(^{*}\right)$ & $39.27(* \star)$ \\
\hline Storage Reservoirs & $0.214(* \star *)$ & $34.38\left(^{*}\right)$ & $39.79\left(^{*}\right)$ \\
\hline Losses & $0.172^{(* *)}$ & $26.63(* \star \star \star)$ & $38.91(* \star)$ \\
\hline Cisterns & $0.033(-)$ & $29.32(* * *)$ & $\left.38.688^{(* *}\right)$ \\
\hline Domestic Conservation & $0.050\left(^{*}\right)$ & $27.10\left(^{\star \star \star \star}\right)$ & $36.60(\star \star \star \star \star)$ \\
\hline Irrigation Method & $0.253(* * \star)$ & $37.59(-)$ & $38.61^{(* * *)}$ \\
\hline \multicolumn{4}{|l|}{ Improvements } \\
\hline Domestic Pricing & $0.218(* * *)$ & $\left.25.399^{(\star \star \star \star \star}\right)$ & $38.86(* \star)$ \\
\hline Irrigation Pricing & $0.313(* \star \star \star)$ & 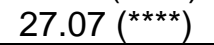 & $38.01(\star \star \star)$ \\
\hline
\end{tabular}


Table 2. Specifications for the alternative water management strategies

\begin{tabular}{|l|l|}
\hline Strategy 1 & Strategy 2 \\
\hline Groundwater Exploitation & Network Unifications \\
A total of 4 additional boreholes, yielding & Groundwater Exploitation \\
$204,000 \mathrm{~m}^{3} / \mathrm{yr}$ & 1 additional borehole, yielding $75,000 \mathrm{~m}^{3} / \mathrm{yr}$ \\
Surface water exploitation & Surface water exploitation \\
Interception dam for aquifer enhancement & Interception dam for aquifer enhancement \\
Capacity of $98,000 \mathrm{~m}^{3}$ & Capacity of $98,000 \mathrm{~m}^{3}$ \\
Reduction of Network Losses & Reduction of Network Losses \\
From 25 to $20 \%$ & From 25 to $20 \%$ \\
Desalination & Conservation measures in the hotel sector \\
Additional capacity of: & $10 \%$ reduction of consumption \\
$1300 \mathrm{~m}^{3} / \mathrm{d}$ in 2010 & Irrigation Method Improvement \\
$2000 \mathrm{~m}^{3} / \mathrm{d}$ in 2020 & Substitution of current methods with drip \\
$2700 \mathrm{~m}^{3} / \mathrm{d}$ in 2030 & irrigation \\
& Desalination \\
& Additional Capacity of $600 \mathrm{~m}^{3} / \mathrm{d}$ \\
\hline
\end{tabular}

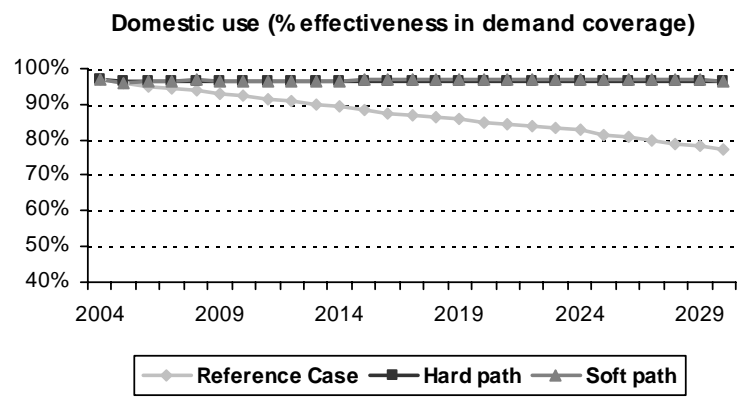

(a)

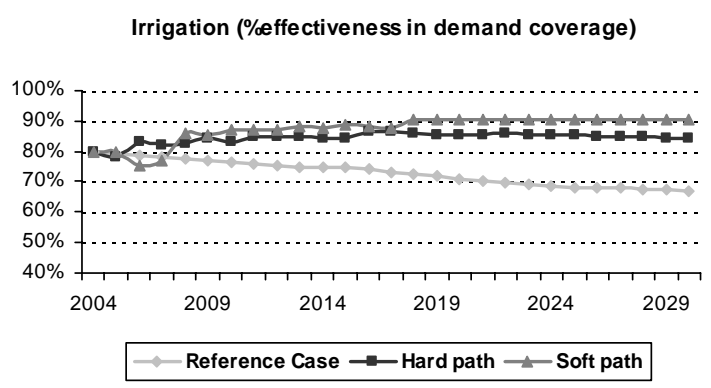

(b)

Figure 5. Effectiveness of the proposed strategies in meeting the set targets (a) domestic use (b) irrigation water provision

The formulation of an appropriate cost recovery scheme for domestic water provision in Stage 2 starts with an assessment of the total allocated costs (financial, environmental and resource costs), and the corresponding cost recovery levels (Figure 6). Under the proposed strategies, cost recovery rate for domestic water provision is low, ranging from 40 to $50 \%$. Although the "hard path" approach entails additional capital investments, cost recovery is higher due to the augmented volume of water production, and revenues from water billing.

On a preliminary basis, the cost recovery scheme adopted (Step 6) was not tiered; flatrate average volumetric prices were estimated instead, to be readjusted after 5-year periods. The set cost recovery targets, to be achieved through a gradual increase of prices, were (a) a $100 \%$ recovery of financial costs for the total duration of the examined period (2005-2030), and (b) an initial (in the year 2005) recovery of 50\% of environmental costs, progressively rising to a 70\% recovery in 2030. For Strategy 1 this initially defined an average price ranging from $1.44 € / \mathrm{m}^{3}$ in 2004 to $2.37 € / \mathrm{m}^{3}$ in 2005 and $2.45 € / \mathrm{m}^{3}$ in 2025. Initially estimated prices for Strategy 2 were higher at the end of the examined period ranging from $2.31 € / \mathrm{m}^{3}$ in 2005 to $2.36 € / \mathrm{m}^{3}$ in $2015,2.48 € / \mathrm{m}^{3}$ in 2020 and 2.63 $€ / \mathrm{m}^{3}$ in 2025. 


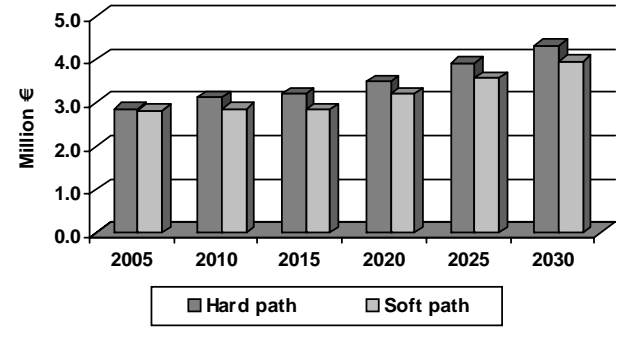

(a)

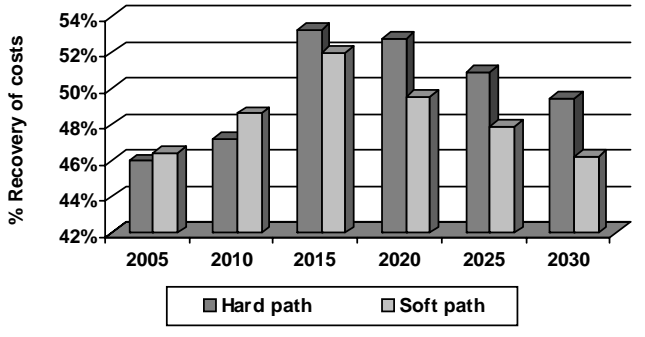

(b)

Figure 6. (a) Total environmental and direct costs allocated to domestic use and (b) cost recovery rate for the two evaluated strategies

As the elevated water prices influence water demand, each strategy was re-evaluated, incorporating the new pricing system. Assuming a demand elasticity for domestic water provision of -0.2 , the introduction of pricing is expected to significantly affect the demand. Therefore an iterative process was used in order to redefine the extent for the application of options, their costs, and the prices required for the targeted cost recovery. By this process, the final prices for domestic supply in the year 2030 were determined at $2.32 € / \mathrm{m}^{3}$ for both Strategies. Following the re-adjustment of the two Strategies to reflect the effects of pricing, their performance was re-evaluated in Step 7. The re-evaluation results are shown in Table 3.

Table 3. Adjusted strategy evaluation table under a cost recovery scheme (values before re-adjustment are in brackets)

\begin{tabular}{|l|c|c|c|c|}
\hline & \multirow{2}{*}{$\begin{array}{c}\text { Relative Sustainability } \\
\text { Index for Demand } \\
\text { Coverage }\end{array}$} & \multicolumn{2}{|c|}{ Present Value (2004-2030), 4\%, Million $€$} \\
\cline { 3 - 5 } & 0.000 & 27.59 & 36.07 & 5.07 \\
\hline Reference & $0.503(0.507)$ & $31.07(33.99)$ & $35.19(35.89)$ & $1.16(3.88)$ \\
\hline Strategy 1 & $0.502(0.503)$ & $27.38(30.33)$ & $32.18(33.84)$ & $0.59(1.60)$ \\
\hline Strategy 2 & &
\end{tabular}

The final cost recovery achieved, as a result of the new tariffs is presented in Figure 7.

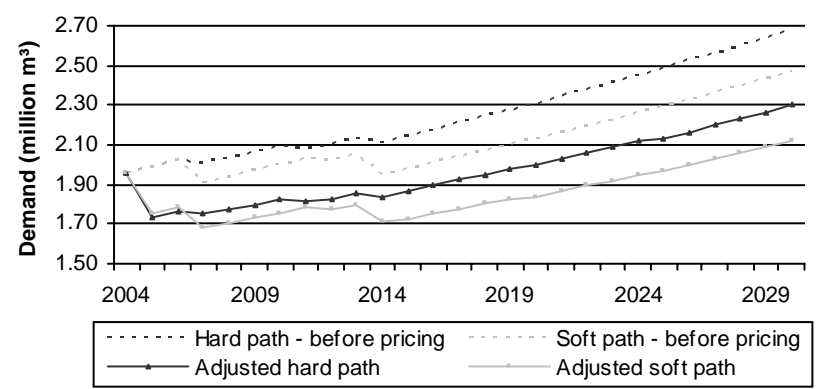

(a)

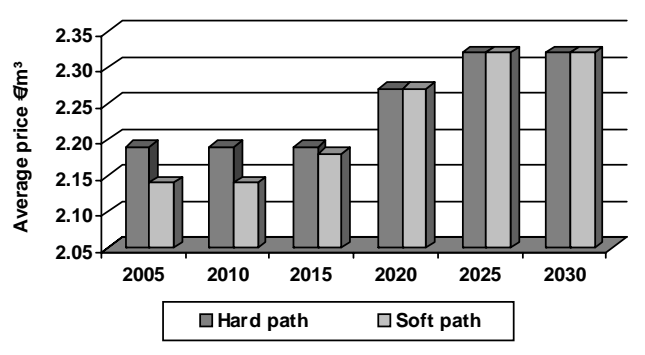

(b)

Figure 7. (a) Domestic Demand (million $\mathrm{m}^{3}$ ) before and after the applied cost recovery scheme and (b) Final average prices for domestic water supply

\section{CONCLUSIONS}

Following the final evaluation of the two Strategies against each other and the reference case, it can be inferred that pricing will not influence the size of the infrastructure needed for the coverage of demand. The total water consumption (including both domestic use and irrigation) remains the same as the demand decrease in the domestic sector only 
means that the water volumes available to irrigation are increased. Due to the current institutional framework, pricing of irrigation water is an instrument that cannot be implemented, although for private supplies it could take the form of abstraction charges and penalties for overabstraction; a subsidy is therefore always present between the domestic and agricultural use of water. The evaluation results for the "soft-path" approach (Strategy 2) compared to the reference case and the "hard-path" approach (Strategy 1) emphasise that the high temporal water imbalance in the island can best be solved through a combination of small-scale decentralised structural measures and soft interventions aiming to increase the efficiency and productivity of water use. Such a conclusion is further strengthened by the lower costs incurred to consumers due to the adoption of "soft" responses to mitigate water stress.

This example further serves to illustrate that under suitable supply management and allocation schemes the recovery of water-service related costs can result in the more equitable allocation of available resources, while at the same time incurring lower costs for water service provision, both to the users and to the utility, and thus promoting the financial sustainability of the water services. Given a strong regulatory framework that ensures the sustainable management of available water resources, and that the local economic activities and general public well-being are safeguarded, these conditions apply both to public and private water supply providers. Finally, it should be stressed that the development of a visionary and successful programme of measures should always be a participatory process; only then can all social concerns and conflicts be addressed in a satisfactory manner, providing solutions that will be to the best interest of both society and the environment.

\section{REFERENCES}

1. Brundtland, G (ed) (1987). Our Common Future: The World Commission on Environment and Development, Oxford: Oxford University Press.

2. Le Moigne G., Subramanian A. (1994), 'A guide to the formulation of Water Resources Strategy', World Bank Technical Paper No 263.

3. Food and Agriculture Organization of the United Nations, FAO Glossary, FAO/Netherlands International Conference Website, Accessed on December $20^{\text {th }} 2005$, http://www.fao.org/ag/wfe2005/glossary en.htm

4. Assimacopoulos D. (2004), 'An Integrated Decision Support System for the evaluation of water management strategies', IDS-Water Europe web conference, May 2004.

5. Jønch-Clausen T. (2004), '...Integrated Water Resources Management (IWRM) and Water Efficiency Plans by 2005. Why, What and How?', TAC Background papers, No 10, Global Water Partnership.

6. DIRECTIVE 2000/60/EC OF THE EUROPEAN PARLIAMENT AND OF THE COUNCIL of 23 October 2000 establishing a framework for Community action in the field of water policy.

7. Task Committee on Sustainability Criteria, Water Resources Planning and Management Division, ASCE and Working Group of UNESCO/IHP IV Project M-4.3 (1998), Sustainability Criteria for Water Resource Systems, ASCE Publications, Virginia.

8. WaterStrategyMan (2005), 'Comprehensive Water Management Scenarios', Deliverable No 16 of the project 'Developing Strategies for Regulating and Managing Water Resources and Demand in Water Deficient Regions', EU DG Research, EVK1-CT-2001-00098, URL: http://environ.chemeng.ntua.gr/wsm/

9. Gleick P.H. (2003), 'Global Freshwater Resources: Soft-Path Solutions for the $21^{\text {st }}$ Century', Science, 302, 1524-1528.

10. World Bank (2002), 'Water Resources Sector Strategy: Strategic directions for World Bank engagement', Draft for discussion of March 25. 